\title{
PRESSURIZAÇÃO DA CALDA DE PULVERIZAÇÃO NA VIABILIDADE DE MICRORGANISMOS ENTOMOPATOGÊNICOS ${ }^{1}$
}

\section{LUIZ C. GARCIA ${ }^{2}$, CARLOS G. RAETANO ${ }^{3}$, SILVIA R. S. WILCKEN ${ }^{3}$, HAMILTON H. RAMOS $^{4}$, LUIS G. LEITE $^{5}$, ANTÔNIO B. FILHO ${ }^{5}$, FLÁVIO MOSCARDI $^{6}$}

\begin{abstract}
RESUMO: Avaliou-se a influência da pressurização da calda de pulverização na viabilidade dos seguintes microrganismos entomopatogênicos: o fungo Metarhizium anisopliae, a bactéria Bacillus thuringiensis var. kurstaki, o nucleopoliedrovirus de Anticarsia gemmatalis (AgMNPV) e o nematóide Steinernema glaseri. Utilizou-se do sistema hidráulico de um pulverizador, sem filtros, equipado com ponta de pulverização de jato cônico JA-2. O delineamento experimental adotado foi o inteiramente casualizado, com sete tratamentos: pressurização da calda em 172; 345; 517; 689; 1.034 e $1.379 \mathrm{MPa}$, e a testemunha (calda não submetida à pressurização). A avaliação da viabilidade de $M$. anisopliae foi realizada por meio da porcentagem de germinação dos conídios. Para B. thuringiensis, foi considerado o número de colônias. A eficácia do AgMNPV foi estimada indiretamente, pela mortalidade causada às lagartas de $A$. gemmatalis no início do terceiro instar, alimentadas com dieta artificial impregnada com suspensão viral. No caso do $S$. glaseri, foi calculada a porcentagem de indivíduos vivos em lâmina de Peters. Conclui-se que se podem pulverizar os entomopatógenos $M$. anisopliae, $B$. thuringiensis, AgMNPV e S. glaseri, até a pressão de $1.379 \mathrm{MPa}$, sem que haja perda na viabilidade desses organismos utilizados como agentes de controle biológico.
\end{abstract}

PALAVRAS-CHAVE: tecnologia de aplicação, controle biológico.

\section{PRESSURIZATION OF THE SPRAYING SUSPENSION AND VIABILITY OF ENTOMOPATHOGENS}

\begin{abstract}
The objective of this research was to evaluate the influence of spraying pressurization upon the viability of the following entomopathogens microorganisms: the fungus Metarhizium anisopliae, the bacterium Bacillus thuringiensis var. kurstaki, the nucleopolyhedrovirus of Anticarsia gemmatalis (AgMNPV), and the nematode Steinernema glaseri. The sprayer hydraulical system was used without filters and equipped with JA-2 hollow-cone nozzle type. The experimental design was completely randomized, with seven treatments: pressurization of spraying suspension at $172 ; 345 ; 517$; $689 ; 1,034$ and 1,379 MPa, and check (suspension not submitted to the pressurization). Evaluation of the viability of $M$. anisopliae was estimated by the percentage of germinated conidia. For $B$. thuringiensis, by the number of colonies formed. Efficiency on AgMNPV was estimated indirectly, by means of mortality caused to A. gemmatalis infected as early third-instars larvae reared in an artificial diet impregnated with the viral suspension. For the experiment with $S$. glaseri it was calculated the percentage of live specimens on Peters slide-blade. It concluded that the entomopathogens $M$. anisopliae, B. thuringiensis, AgMNPV and S. glaseri can be sprayed up to the pressure of 1,379 $\mathrm{MPa}$ without losing the viability of those organisms as biological control agents.
\end{abstract}

KEYWORDS: application technology, biological control.

\footnotetext{
${ }^{1}$ Extraído da dissertação de mestrado do primeiro autor. Bolsista FAPESP.

2 Pós-Graduando em Proteção de Plantas, Faculdade de Ciências Agronômicas, Fazenda Experimental do Lageado, Caixa Postal 237, Botucatu - SP, Fone: (0XX14) 3811.7205, lcgarcia@ fca.unesp.br.

${ }^{3}$ Profs. Doutores, Departamento de Produção Vegetal, FCA/UNESP, Botucatu - SP.

${ }^{4}$ Doutor, Centro Avançado de Pesquisa Tecnológica do Agronegócio de Engenharia e Automação - IAC, Jundiaí - SP.

${ }^{5}$ Doutores, Centro Experimental do Instituto Biológico, Campinas - SP.

${ }^{6}$ Doutor, Embrapa Soja, Londrina - PR.

Recebido pelo Conselho Editorial em: 4-3-2004

Aprovado pelo Conselho Editorial em: 25-8-2005
} 


\section{INTRODUÇÃO}

O controle biológico de pragas tem-se destacado como opção ao controle químico, pela busca de produtos fitossanitários que minimizem os danos à saúde do agricultor, do consumidor e ao ambiente. $\mathrm{O}$ uso de bioinseticidas à base de fungos, bactérias, vírus e nematóides entomopatogênicos tem aumentado no País. No entanto, as aplicações desses agentes biológicos têm sido realizadas com as mesmas técnicas de pulverização desenvolvidas para produtos químicos, sem nenhuma avaliação prévia dos possíveis danos que os equipamentos poderiam causar à viabilidade de tais organismos (ALVES, 1986).

Partindo do pressuposto que está pulverizando organismos vivos, estima-se que a pressurização da calda e o atrito desses organismos às partes internas do circuito hidráulico podem causar danos físicos às suas estruturas de propagação. Da mesma forma, a despressurização, em curto intervalo de tempo, antecedendo e imediatamente após a pulverização, pode estar reduzindo o número de estruturas viáveis para o controle de determinado inseto-praga e, conseqüentemente, a eficácia do bioinseticida.

Em testes envolvendo pressurização e despressurização na pulverização de fungos entomopatogênicos, NILSSON \& GRIPWALL (1999) submeteram vários produtos comerciais à base de blastóporos e conídios de Verticillium lecanii às pressões de $1 \times 10^{3} ; 3 \times 10^{3}$ e $5 \times 10^{3} \mathrm{MPa}$. Os autores concluíram que a pressão de $1 \times 10^{3} \mathrm{MPa}$ não influiu significativamente na viabilidade relativa do fungo; porém, na pressão de $3 \times 10^{3} \mathrm{MPa}$, a viabilidade caiu de 100 para cerca de $80 \%$, e com $5 \times 10^{3} \mathrm{MPa}$ chegou-se somente a $45 \%$ de viabilidade relativa de blastóporos e conídios de $V$. lecanii. Esporos do gênero Bacillus, em ensaios conduzidos por MUNAKATA \& RUPERT (1972), suportaram pressurização de até $6 \times 10^{5} \mathrm{MPa}$, em diferentes períodos e temperaturas, sem que sua viabilidade fosse afetada. MOSCARDI (1999) e SILVA \& MOSCARDI (2001) estudaram a formulação, $\mathrm{pH}$ da calda, volume da calda e horário de aplicação do AgMNPV, porém não analisaram a influência da pressurização e da despressurizarão da calda pulverizada na viabilidade do referido entomopatógeno. Segundo POINAR JÚNIOR (1986) e AGUILLERA (2003), não há alteração significativa na viabilidade de nematóides entomopatogênicos pulverizados com pressões de até $2.068 \mathrm{MPa}$.

O objetivo deste experimento foi avaliar a influência da pressurização da calda de pulverização, em até $1.379 \mathrm{MPa}$, na viabilidade dos seguintes microrganismos entomopatogênicos: o fungo Metarhizium anisopliae, a bactéria Bacillus thuringiensis var. kurstaki, o nucleopoliedrovirus de $A$. gemmatalis (AgMNPV) e o nematóide Steinernema glaseri.

\section{MATERIAL E MÉTODOS}

O pulverizador empregado no experimento foi do tipo semi-estacionário, com motor elétrico trifásico de 2,9 kW (4,0 cv); bomba de três pistões, modelo JP 42A, pressão máxima de 3,5 x $10^{3} \mathrm{MPa}$, rotação de $800 \mathrm{rpm}$, vazão de $42 \mathrm{~L} \mathrm{~min}^{-1}$ e tanque com capacidade de $600 \mathrm{~L}$. A ponta de pulverização escolhida foi a de jato cônico JA-2, por atender às especificações das pressões estabelecidas para o experimento (JACTO, 2002). Todos os filtros do sistema hidráulico (do tanque, de linha e do bico) foram retirados, evitando que essa variável influenciasse nos resultados do experimento.

$\mathrm{O}$ volume de calda estabelecido para todos os entomopatógenos foi $200 \mathrm{~L} \mathrm{ha}^{-1}$. O solvente utilizado foi a água, deionizada e esterilizada, para evitar o desenvolvimento de contaminantes nos tratamentos do experimento. $\mathrm{O} \mathrm{pH}$ do solvente variou de 6,1 a 6,8. A pulverização da calda ocorreu em ambiente com temperatura entre 10 e $25{ }^{\circ} \mathrm{C}$ e umidade relativa do ar acima de $50 \%$, como indica a International Standardization Organization - ISO (1996). Seguindo o método proposto por NILSSON \& GRIPWALL (1999), antes da coleta da suspensão de cada tratamento, o sistema de agitação do pulverizador foi acionado durante 15 minutos, para homogeneização da calda. 
A escolha de $M$. anisopliae, B. thuringiensis, AgMNPV e S. glaseri deu-se pela importância desses entomopatógenos em programas de controle biológico no Brasil. Antes da aplicação de cada organismo, todo o sistema hidráulico foi limpo pela passagem de água deionizada e esterilizada, durante 15 minutos, seguido de tríplice lavagem no tanque com o mesmo solvente. Assim, reduziramse as chances de contaminação durante a coleta das suspensões contendo os entomopatógenos.

O delineamento experimental adotado, para os diferentes entomopatógenos, foi inteiramente casualizado, com sete tratamentos: pressurização da calda em $172 ; 344 ; 517 ; 689 ; 1.034 ; 1.379 \mathrm{MPa}$ e a testemunha (calda não submetida à pressurização). A escolha dessas pressões deveu-se à faixa de trabalho indicada para maior parte das pontas empregadas na pulverização de entomopatógenos. Foram realizadas cinco repetições para $M$. anisopliae e $B$. thuringiensis, dez para AgMNPV e seis para S. glaseri. A diferença do número de repetições deu-se pelas particularidades de análise e tamanho da amostra.

Os dados (número de esporos germinados, colônias bacterianas, número de lagartas infectadas e concentração de partículas virais e número de nematóides viáveis) foram submetidos à verificação da homocedasticidade das variâncias, pelo teste de Hartley, à análise de variância (ANOVA), pelo teste "F", e à comparação de médias, pelo teste LSD, a 5,0\% de probabilidade.

O experimento inerente ao $M$. anisopliae foi realizado no Centro Experimental do Instituto Biológico, Campinas - SP. O pulverizador semi-estacionário foi cedido pelo Centro Avançado de Pesquisa Tecnológica do Agronegócio de Engenharia e Automação - IAC, Jundiaí - SP. A concentração utilizada foi de $2,5 \times 10^{10}$ conídios por litro, do isolado de IBCB 348, obtido de Mahanarva fimbriolata. A suspensão pulverizada proveniente de cada tratamento foi coletada em recipiente esterilizado e posteriormente inoculada em placa de Petri, com alíquotas de 0,1 mL, em meio contendo Batata Dextrose Ágar (200 g de batata, $20 \mathrm{~g}$ de Dextrose, $20 \mathrm{~g}$ de Ágar, $1 \mathrm{~L}$ de água destilada e 0,25 g de Pentabiótico) e espalhada com o auxílio da alça de Drigalsky. Tal procedimento teve como intuito estimular a germinação do $M$. anisopliae. Após o período de incubação $\left(24,1{ }^{\circ} \mathrm{C}\right.$ por $14 \mathrm{~h}$ ), o fungo foi observado em microscópio óptico (400x), a fim de calcular a porcentagem de esporos germinados (ALVES \& MORAES, 1998). O tamanho da amostra foi definido pelo método proposto por KRANZ (1988), que considera a estabilização da média e/ou desvio-padrão dos dados coletados e plotados em gráfico.

No que se refere ao $B$. thuringiensis, o experimento foi realizado no Centro Experimental do Instituto Biológico, Campinas - SP, utilizando-se do pulverizador semi-estacionário do IAC, Jundiaí SP. Foi utilizada a concentração de $1,0 \mathrm{~g} \mathrm{~L}^{-1}$ do produto comercial DIPEL ${ }^{\circledR}$ PM. A suspensão pulverizada, proveniente de cada tratamento, foi coletada em Becker de $500 \mathrm{~mL}$, sendo posteriormente submetida a um período de 10 minutos a $80^{\circ} \mathrm{C}$, em "banho-maria", visando à eliminação de contaminantes. Foram realizadas sete diluições sucessivas, a partir de 1,0 mL da suspensão, adicionando-se 9,0 $\mathrm{mL}$ de água destilada, para determinar a diluição que possibilitasse a melhor quantificação das colônias. Posteriormente, o plaqueamento foi realizado em "meio L" (10 g de Peptona, $5 \mathrm{~g}$ de extrato de levedura, $5 \mathrm{~g}$ de cloreto de sódio, $15 \mathrm{~g}$ de Agar e 1,0 L de água destilada), e o material transferido para ambiente controlado $\left(28^{\circ} \mathrm{C}\right)$, o qual foi mantido por $17 \mathrm{~h}$. Ao final desse período, escolheu-se a melhor diluição e fez-se a contagem do número de colônias dos respectivos tratamentos.

As etapas do experimento com AgMNPV foram realizadas na Embrapa Soja, Londrina - PR. Em função da necessidade de organismos ou células vivas para a sua multiplicação, optou-se pela realização de bioensaio, com lagartas de Anticarsia gemmatalis de terceiro instar, para verificação da influência da pressurização da calda de pulverização contendo AgMNPV. Foi pulverizado $0,1 \mathrm{~g} \mathrm{~L}^{-1} \mathrm{de}$ uma formulação PM (experimental), produzida na Embrapa Soja, a qual continha, no mínimo, 7,5 x $10^{9}$ corpos poliédricos de inclusão (CPI) $\mathrm{g}^{-1}$. Coletou-se a suspensão dos tratamentos e, após 
homogeneização do material e contagem dos CPI em câmara de Neubauer, foi preparada a diluição de lote ajustada para 1,6 x $10^{4} \mathrm{CPI} \mathrm{mL}^{-1}$. A dieta artificial para A. gemmatalis foi preparada de acordo com HOFFMANN et al. (1985). Depois de preparada, a dieta foi resfriada a $50{ }^{\circ} \mathrm{C}$ e misturada, em Becker, à suspensão com vírus, na proporção de $10 \mathrm{~mL}$ da suspensão para $90 \mathrm{~mL}$ de dieta. Assim, a concentração viral resultante foi $1,6 \times 10^{3} \mathrm{CPI} \mathrm{mL}^{-1}$. O controle da mortalidade das lagartas de $A$. gemmatalis por fatores não controlados foi realizado em dieta artificial não inoculada pelo AgMNPV (10 mL de água destilada misturada a $90 \mathrm{~mL}$ de dieta). A eficácia do produto utilizado no teste foi verificada pela inclusão do tratamento com dieta artificial inoculada pelo AgMNPV-padrão da Embrapa Soja, que é utilizado no controle de qualidade de lotes de AgMNPV formulados nesse centro de pesquisa. Colocaram-se $10 \mathrm{~mL}$ de dieta em copos plásticos com capacidade de $50 \mathrm{~mL}$, deixando-se à temperatura ambiente para resfriamento. O tamanho da amostra (número de lagartas de $A$. gemmatalis, no início do terceiro ínstar, por copo plástico com dieta artificial) foi definido pelo método proposto por KRANZ (1988). As lagartas foram mantidas em câmara climatizada (BOD), à temperatura de $26 \pm 2{ }^{\circ} \mathrm{C}$, umidade relativa de $70 \pm 20 \%$, e fotofase de $14 \mathrm{~h}$. A avaliação foi realizada por meio do registro da mortalidade de lagartas e seu agente causal, ao $12^{\underline{0}}$ dia do fornecimento de dieta artificial contaminada pelo AgMNPV, quando as larvas sobreviventes normalmente empupam.

O estudo com $S$. glaseri foi realizado nos laboratórios de Tecnologia de Aplicação de Produtos Fitossanitários e de Nematologia, do Departamento de Produção Vegetal, Defesa Fitossanitária da Faculdade de Ciências Agronômicas - UNESP, Câmpus de Botucatu - SP. A multiplicação desse entomopatógeno foi realizada em larvas da traça-das-colméias (Galleria mellonella). A concentração empregada foi de 75 mil juvenis infectivos por litro. Após a passagem da calda pelo circuito hidráulico, sob as diferentes pressões, coletou-se $1,0 \mathrm{~L}$ da calda dos respectivos tratamentos e peneirou-se a suspensão em malha 500, convertendo a quantidade de juvenis infectivos por litro para 20,0 mL. Procedeu-se à determinação, em microscópio esteroscópio com aumento de 40x, da porcentagem de juvenis infectivos viáveis por $\mathrm{mL}$, com o auxílio da lâmina de Peters, após 5,0 minutos da passagem pelo circuito hidráulico. $\mathrm{O}$ tamanho da amostra também foi definido pelo método proposto por KRANZ (1988).

\section{RESULTADOS E DISCUSSÃO}

$\mathrm{Na}$ definição do tamanho da amostra para o isolado IBCB-348 de $M$. anisopliae, houve estabilização da média e desvio-padrão da porcentagem de conídios germinados com 100 conídios contabilizados por repetição, nas condições deste experimento. Porém, pelo número extremamente maior de conídios por placa de Petri, optou-se por analisar 200 conídios por repetição. O teste de Hartley apontou homocedasticidade das variâncias, não sendo necessária a transformação dos dados. $\mathrm{O}$ teste "F" não indicou diferenças significativas entre os tratamentos, não havendo necessidade da aplicação do teste LSD (Tabela 1). Os conídios de M. anisopliae suportaram a pressurização da calda sem que houvesse diferença significativa na sua capacidade de germinação em meio de cultura, com grau de confiança superior a $95 \%$ de probabilidade. Os resultados obtidos confirmam os testes realizados com outro fungo ( $V$. lecanii) por NILSSON \& GRIPWALL (1999), em que os autores concluíram que somente as pressurizações da calda acima de $3 \times 10^{3} \mathrm{MPa}$ influem significativamente na viabilidade relativa dos conídios do fungo.

A melhor diluição obtida no método empregado para a contagem do número de colônias de $B$. thuringiensis por placa de Petri foi de $10^{-5}$ em relação à dosagem original de $200 \mathrm{~g} \mathrm{ha}^{-1}$ do produto comercial DIPEL ${ }^{\circledR}$ PM. Nessa diluição, podem-se contar, de forma clara, 18 colônias, em média, por placa de Petri. O teste de Hartley apontou homocedasticidade das variâncias, não sendo necessária a transformação da média do número de colônias por placa de Petri. O teste " $F$ " não indicou diferenças significativas entre tratamentos, não havendo necessidade da aplicação do teste LSD (Tabela 2). Dessa forma, pode-se afirmar que os esporos de $B$. thuringiensis não foram influenciados pela pressurização 
da calda em até $1.379 \mathrm{MPa}$. No ensaio conduzido por MUNAKATA \& RUPERT (1972), a pressão de $6 \times 10^{5} \mathrm{MPa}$ superou em muito aquelas normalmente utilizadas na pressurização da calda de pulverização com entomopatógenos. Contudo, mesmo em condições extremas, a viabilidade dos esporos do gênero Bacillus não foi afetada. Além da resistência da bactéria à compressão promovida pela pressurização, constatou-se, neste experimento, a tolerância do organismo à despressurização da calda quando lançada pelo sistema hidráulico do pulverizador.

TABELA 1. Viabilidade de conídios germinados de Metarhizium anisopliae, isolado IBCB 348, obtido de Mahanarva fimbriolata, concentração de 2,5 x $10^{10}$ conídios por litro, em placa de Petri com batata dextrose ágar (BDA), após serem submetidos a diferentes níveis de pressurização da calda de pulverização.

\begin{tabular}{cc}
\hline Pressão $(\mathrm{MPa})$ & Germinação $(\%)$ \\
\hline Testemunha (calda não submetida à pressurização) & $83,2^{(1)}$ \\
172 & 83,2 \\
345 & 80,2 \\
517 & 80,2 \\
689 & 80,8 \\
1.034 & 80,4 \\
1.379 & 81,2 \\
\hline
\end{tabular}

Desvio-Padrão $=3,71$

Erro-Padrão da Média $=1,66$

Média Geral $=81,31$

Coeficiente de Variação $=4,57$

${ }^{(1)}$ Não significativo pelo teste " $F$ ", a $5 \%$ de probabilidade $(\mathrm{P}>0,05)$.

TABELA 2. Número de colônias formadas a partir de esporos de Bacillus thuringiensis (diluição de $10^{-5}$ da concentração de $1,0 \mathrm{~g} \mathrm{~L}^{-1}$ do produto comercial Dipel ${ }^{\circledR} \mathrm{PM}$ ) em meio "L", após serem submetidos a diferentes níveis de pressurização da calda de pulverização.

\begin{tabular}{lc}
\hline Pressão $(\mathrm{MPa})$ & Número de Colônias (unidades) \\
\hline Testemunha (calda não submetida à pressurização) & $17,4^{(1)}$ \\
172 & 19,0 \\
345 & 21,4 \\
517 & 17,0 \\
689 & 17,0 \\
1.034 & 17,0 \\
1.379 & 17,2 \\
\hline Desvio-Padrão = 4,79 & Erro-Padrão da Média $=2,14$ \\
Média Geral = $=$ & Coeficiente de Variação $=26,63$ \\
(1) NS - não significativo pelo teste "F", a 5\% de probabilidade $(\mathrm{P}>0,05)$.
\end{tabular}

${ }^{(1)} \mathrm{NS}$ - não significativo pelo teste " $\mathrm{F}$ ", a $5 \%$ de probabilidade $(\mathrm{P}>0,05)$.

Com respeito ao ensaio com AgMNPV, a média e o desvio-padrão se estabilizaram com duas lagartas por parcela ou copo. Contudo, em função da possibilidade de inclusão de mais uma lagarta no recipiente de $50 \mathrm{~mL}$, optou-se por três lagartas. O teste de Hartley apontou homocedasticidade das variâncias, não sendo necessária a transformação dos dados. O teste "F" indicou diferenças significativas entre os tratamentos, com grau de confiança superior a $99 \%$ de probabilidade. Os tratamentos envolvendo as pressurizações da calda em até $1.379 \mathrm{MPa}$ e AgMNPV-padrão não diferiram significativamente entre si no que se refere à eficácia na mortalidade de lagartas de $A$. gemmatalis, com média de $83,34 \%$, pelo teste LSD, a 5,0\%. Os referidos tratamentos só diferiram significativamente da testemunha, com $3,3 \%$ de mortalidade, que, nesse caso, representou a 
alimentação das lagartas com dieta sem impregnação do AgMNPV (Tabela 3). Evidencia-se que as pressões utilizadas não afetaram a atividade do AgMNPV.

TABELA 3. Mortalidade de lagartas de Anticarsia gemmatalis, em terceiro instar, pela ação do AgMNPV, no $12^{\circ}$ dia em dieta artificial com $4,9 \times 10^{3} \mathrm{CPI} \mathrm{mL}^{-1}$, após serem submetidas a diferentes níveis de pressurização da calda de pulverização.

\begin{tabular}{|c|c|}
\hline Pressão $(\mathrm{MPa})$ & Mortalidade $(\%)$ \\
\hline Testemunha 1 (dieta artificial não inoculada pelo AgMNPV) & $3,3 b^{(1)}$ \\
\hline Testemunha 2 (calda não submetida à pressurização) & 93,3 a \\
\hline 172 & $96,7 \mathrm{a}$ \\
\hline 345 & $90,0 \mathrm{a}$ \\
\hline 517 & $96,7 \mathrm{a}$ \\
\hline 689 & 93,3 a \\
\hline 1.034 & $90,0 \mathrm{a}$ \\
\hline 1.379 & $90,0 \mathrm{a}$ \\
\hline AgMNPV-Padrão & $96,7 \mathrm{a}$ \\
\hline Desvio-Padrão $=13,39$ & Erro-Padrão da Média $=$ \\
\hline Média Geral $=83,34$ & Coeficiente de variação $=16,07$ \\
\hline
\end{tabular}

No caso do nematóide entomopatogênico S. glaseri, a estabilização ocorreu com dez juvenis infectivos por lâmina de Peters (Figura 3). Todavia, devido à dificuldade de precisar o número de nematóides por volume, a verificação da porcentagem de juvenis infectivos viáveis teve variação de nove a 20 indivíduos por lâmina de Peters. Portanto, foi possível trabalhar com o intervalo de nematóides nas amostras das parcelas compatível com o método proposto por KRANZ (1988), conferindo confiabilidade estatística à análise dos dados.

O teste de Hartley apontou homocedasticidade das variâncias, não sendo necessária a transformação dos dados. O teste " $F$ " não indicou diferenças significativas entre os tratamentos. Dessa forma, os juvenis infectivos de $S$. glaseri suportaram os diferentes níveis de pressurização da calda sem que houvesse diferença significativa na porcentagem de juvenis infectivos viáveis, com grau de confiança superior a $95 \%$ de probabilidade (Tabela 4).

Os resultados obtidos com $S$. glaseri corroboram as afirmações de POINAR (1986) e AGUILLERA (2003), que concluíram que somente a pressurização da calda acima de $2 \times 10^{3} \mathrm{MPa}$ influem significativamente na viabilidade relativa de juvenis infectivos de nematóides entomopatogênicos. É importante ressaltar a necessidade da retirada dos filtros do sistema hidráulico. Com certeza, esses filtros impediriam a passagem do nematóide $S$. glaseri, pois o comprimento médio da forma infectiva empregada no experimento foi de $1.130 \mu \mathrm{m}$. A maior malha compatível com as pontas comumente utilizadas na aplicação de agrotóxicos é de número 50, que representa 50 orifícios por polegada. Se uma polegada tem $25.400 \mu \mathrm{m}$, o resultante da divisão por 50 é igual a $508 \mu \mathrm{m}$; valor esse já $45 \%$ inferior ao tamanho médio do nematóide.

Com relação à faixa de pressão empregada na aplicação de agrotóxicos, podem-se utilizar os mesmos parâmetros para a pulverização dos entomopatógenos testados neste experimento, sem custos de adaptação das máquinas às particularidades dos organismos. 
TABELA 4. Juvenis infectivos viáveis de Steinernema glaseri, concentração de 75 mil juvenis infectivos por litro, após serem submetidos a diferentes níveis de pressurização da calda de pulverização.

\begin{tabular}{cc}
\hline Pressão $(\mathrm{MPa})$ & Juvenis Infectivos Viáveis (\%) \\
\hline Testemunha (calda não submetida à pressurização) & $87,3^{(1)}$ \\
172 & 82,0 \\
345 & 87,8 \\
517 & 86,7 \\
689 & 85,3 \\
1.034 & 84,2 \\
1.379 & 83,2 \\
\hline
\end{tabular}

Desvio-Padrão $=6,07$

Erro-Padrão da Média $=2,48$

Média Geral $=85,21 \quad$ Coeficiente de Variação $=7,12$

${ }^{(1)} \mathrm{NS}$ - não significativo pelo teste " $\mathrm{F}$ ", a $5 \%$ de probabilidade $(\mathrm{P}>0,05)$.

\section{CONCLUSÕES}

Os entomopatógenos Metarhizium anisopliae, Bacillus thuringiensis, AgMNPV e Steinernema glaseri podem ser pulverizados com pressões de até $1.379 \mathrm{MPa}$ sem que haja perdas na viabilidade desses organismos.

\section{AGRADECIMENTOS}

À Fundação de Amparo à Pesquisa do Estado de São Paulo (FAPESP), pelo suporte financeiro. Aos pesquisadores, laboratoristas e técnicos de laboratório do Instituto Biológico, IAC, Embrapa Soja e UNESP, pelo suporte técnico.

\section{REFERÊNCIAS}

AGUILLERA, M. M. Nematóides benéficos controlam pragas na agricultura. Disponível em: $<$ http://www.cnpma.embrapa.br/informativo/index.html>. Acesso em: 18 jan. 2003.

ALVES, S. B. Controle microbiano de insetos. São Paulo: Manole, 1986. 407 p.

ALVES, S. B.; MORAES, S. A. Quantificação de inóculo de patógeno de insetos. In: ALVES, B.S. Controle microbiano de insetos. 2.ed. Piracicaba: FEALQ, 1998. p.765-77.

HOFFMANN, C.B; OLIVEIRA, E.B.; MOSCARDI, F. Criação massal da lagarta da soja (Anticarsia gemmatalis). Londrina: EMBRAPA-CNPSo, 1985. 23 p. (Documentos, 10).

INTERNATIONAL STANDARDIZATION ORGANIZATION. ISO 5682-1: equipment for crop protection - spraying equipment. $2^{\text {nd }}$ ed. Geneva, 1996. p.1-9.

JACTO. Produtos. Disponível em: <http://www.jacto.com.br/produtos>. Acesso em: 24 jan. 2002.

KRANZ, J. Measuring plant disease. In: KRANZ, J.; ROTEM, J. (Ed.). Experimental techniques in plant disease epidemiology. Heidelberg: Springer, 1988. p.35-50.

MOSCARDI, F. Assessment of the application of baculoviruses for control of Lepidoptera. Annual Review of Entomology, Palo Alto, v.44, n.1, p.257-89, 1999.

MUNAKATA, N.; RUPERT, C.S. Genetically controlled removal of "spore photoproduct" from deoxyribonucleic acid of ultraviolet-irradiated Bacillus subtilis spores. Journal Bacteriol, New York, v.3, n.111, p.192-8, 1972. 
NILSSON, U.; GRIPWALL, E. Influence of application technique on the viability of the biological control agents Verticillium lecanii and Steinernema feltiae. Crop Protection, Willoughby, v.18, n.3, p.53-9, 1999.

POINAR JUNIOR, G.O. Entomophagous nematodes. In: FRANS, J.M. (Ed.). Biological plantar and health protection. Stuttgart: Frischler Verlag, 1986. p.95.

SILVA, M.T.B.; MOSCARDI, F. Field efficacy of the nucleopolyhedrovirus of Anticarsia gemmatalis Hübner (Lepidoptera: Noctuidae): effect of formulations, water $\mathrm{pH}$, volume and time of application, and type of spray nozzle. Neotropical Entomology, Londrina, v.31, n.1, p.75-83, 2002. 